\title{
Axillary Irradiation with High Tangent Fields for Clinically Node-Negative Breast Cancer: Can 3-D Conformal Radiotherapy with a Field-in-Field Technique Better Control the Axilla?
}

\author{
Naoko Sanukia,c Atsuya Takeda ${ }^{a, c}$ Atsushi Amemiya ${ }^{b}$ Toru Ofuchi ${ }^{b}$ Masato Ono ${ }^{b}$ \\ Haruki Ogata $^{b}$ Ryo Yamagami ${ }^{b}$ Jun Hatayama ${ }^{b}$ Takahisa Eriguchi $^{a}$ Etsuo Kunieda ${ }^{c}$ \\ aRadiation Oncology Center, ${ }^{b}$ Breast Cancer Center, Ofuna Chuo Hospital, Kamakura, 'Department of Radiation Oncology, Tokai University \\ School of Medicine, Isehara, Kanagawa, Japan
}

\section{Keywords}

Breast cancer · Conformal radiotherapy · Sentinel lymph node biopsy

\section{Summary}

Background: The target volume for postoperative breast irradiation is the remaining breast tissue, and the axillary region is not an intentional target volume. Patients and Methods: Between 2001 and 2009, eligible women with pT1-2cN0/pNo(sn) breast cancer underwent breast-conserving therapy without axillary dissection. Treatment outcomes between 2 radiotherapy planning groups, high tangent fields with 2-dimensional (2-D) simulation-based planning and 3-dimensional (3-D) computed tomography-based planning with a field-in-field technique, were compared. The correlating factors for axillary failure were also calculated. Results: In total, 678 patients were eligible. As of May 2009, the median follow-up times for the 2-D ( $n=346)$ and 3-D ( $n=332)$ groups were 94 and 52 months, respectively. Patient characteristics were balanced, except for a younger population in the 2-D group and more lymphovascular invasion in the 3-D group. On multivariate analysis, 2-D planning was the only risk factor for axillary failure. In the 2-D and 3-D groups, the 5 -year cumulative incidences of axillary failure were 8 $(3.1 \%)$ and $1(0.3 \%)$ (log-rank $p=0.009)$, respectively. The respective 5-year overall survival rates were 97.4 and $98.4 \%$ ( $p=0.4)$. Conclusion: High tangent irradiation with 3-D planning improved axillary control compared to that with 2-D planning, suggesting that optimizing axillary dose distribution may impact outcomes.

\section{Schlüsselwörter}

Mammakarzinom · Konforme Radiotherapie .

Sentinelknotenbiopsie

\section{Zusammenfassung}

Hintergrund: Das Zielvolumen für die postoperative Bestrahlung der Mamma ist das restliche Brustgewebe. Die axilläre Region stellt dagegen kein beabsichtigtes Zielvolumen dar. Patientinnen und Methoden: Zwischen 2001 und 2009 wurde bei entsprechend geeigneten Frauen mit einem pT1-2cN0/pNO(sn)-Mammakarzinom eine brusterhaltende Therapie ohne Axilladissektion durchgeführt. Das Outcome zweier Gruppen mit unterschiedlicher Bestrahlungsplanung - hohe Tangenten mit zweidimensionaler (2-D), simulationsbasierter Planung bzw. dreidimensionale (3-D), computertomographiebasierte Planung mit "Field-in-Field»-Technik - wurden verglichen. Desweiteren wurden korrelierende Risikofaktoren für ein axilläres Rezidiv kalkuliert. Ergebnisse: Insgesamt waren 678 Patientinnen für die Studie geeignet. Im Mai 2009 war das mediane Follow-Up in der 2-D-Gruppe ( $n=346$ ) bzw. der 3-D-Gruppe $(n=332) 94$ bzw. 52 Monate. Die Patientenmerkmale waren bis auf ein jüngeres Alter in der 2-D-Gruppe und häufigere lymphovaskulärer Invasion in der 3-D-Gruppe ausgewogen. In der Multivariatanalyse war die 2-D-Planung der einzige Risikofaktor für ein axilläres Rezidiv. Die kumulative 5-Jahres-Inzidenz eines Axillarezidivs war 8 (3,1\%) bzw. $1(0,3 \%)$ in der 2-D- bzw. 3-D-Gruppe (Log-Rank $p=0,009)$. Die 5-Jahres-Gesamtüberlebensrate war 97,4 bzw. 98,4\% $(p=0,4)$. Schlussfolgerung: Durch die Bestrahlung mit hohen Tangenten und 3-D-Planung konnte die Axilla besser unter Kontrolle gebracht werden als mit 2-D-Planung, was andeutet, dass eine optimierte Dosisverteilung in der Axilla positive Auswirkungen auf das Outcome hat.

\section{KARGER \\ Fax +497614520714 \\ Information@Karger.com}

www.karger.com (c) 2013 S. Karger GmbH, Freiburg

$1661-3791 / 13 / 0085-0362 \$ 38.00 / 0$
Dr. Etsuo Kunieda

Department of Radiation Oncology

Tokai University

143 Shimokasuya, Isehara, Kanagawa, 259-1193 Japan

kunieda-mi@umin.ac.jp 


\section{Introduction}

Over the past 30 years, a major change has taken place in the local management of breast cancer, from mastectomy to breast-conserving surgery $[1,2]$. Similarly, axillary dissection has been performed less frequently since the emergence of sentinel lymph node (SLN) biopsy (SLNB); more axilla, as well as breast, has also been preserved. With consistent evidence of the safety of omission of axillary lymph node dissection (ALND) for such patients [3], the NCCN guideline was updated to consider no further axillary surgery for selected patients with a positive SLNB [4].

The target volume for postoperative breast irradiation in patients who have undergone breast-conserving surgery is the remaining breast tissue, and the axillary region is not an intentional target volume. Recently, several reports have been published on the coverage volume or dose-volume histogram of tangential radiation fields with regard to the volume of the axillary region. However, few data exist on the correlation between technical observations and clinical outcomes. We have reported that patients with $\mathrm{cN} 0$ disease were safely treated with axillary lymph node irradiation without ALND $[5,6]$. In 2004, we began to implement computed tomography (CT)-based 3-dimensional (3-D) treatment planning using a field-in-field technique to improve the dose distribution of both the breast and the axilla [7]. In the current study, we retrospectively compared the outcomes of 2 treatment planning groups, one with high tangent fields with 2-dimentional (2-D) simulation-based planning and one with 3-D CT-based planning, in cN0 patients treated without axillary dissection to evaluate the impact of 3-D treatment planning on clinical outcomes of postoperative breast and axillary irradiation.

\section{Patients and Methods}

From April 1983 to May 2009, 4,048 women with invasive breast cancer without distant metastasis underwent curative treatment at our institutions (fig. 1). Since 1988, we have been substituting axillary lymph node irradiation for ALND in patients with cN0 disease [5]. In 1999, we began to increase the use of high tangential irradiation for these patients, followed by the introduction of SLNB, without changing our policy to preserve the axilla [6]. All patients received surgery at Ofuna Chuo (OC) Hospital. Adjuvant or neoadjuvant chemotherapy and hormonal therapy were carried out under a consistent department policy. Until 2006, patients were referred to one of 2 related hospitals to receive postoperative radiotherapy with 2-D treatment planning. CT-based, 3-D planning using a field-in-field technique was started at OC hospital in 2004. This enabled us to compare 2 different high tangent irradiation techniques, 2-D and 3-D. Of the patients treated from June 2001 to May 2009, those with clinical T1-2N0M0 breast carcinoma received breast-conserving therapy with a minimum follow-up of 36 months were included in this analysis. The possible advantages and disadvantages of ALND and axillary lymph node irradiation were explained to each patient. Informed consent was obtained from all patients for the proposed treatment. Patients who had undergone ALND prior to 1988, had synchronous bilateral breast carcinomas, or had received neoadjuvant systemic therapy were excluded

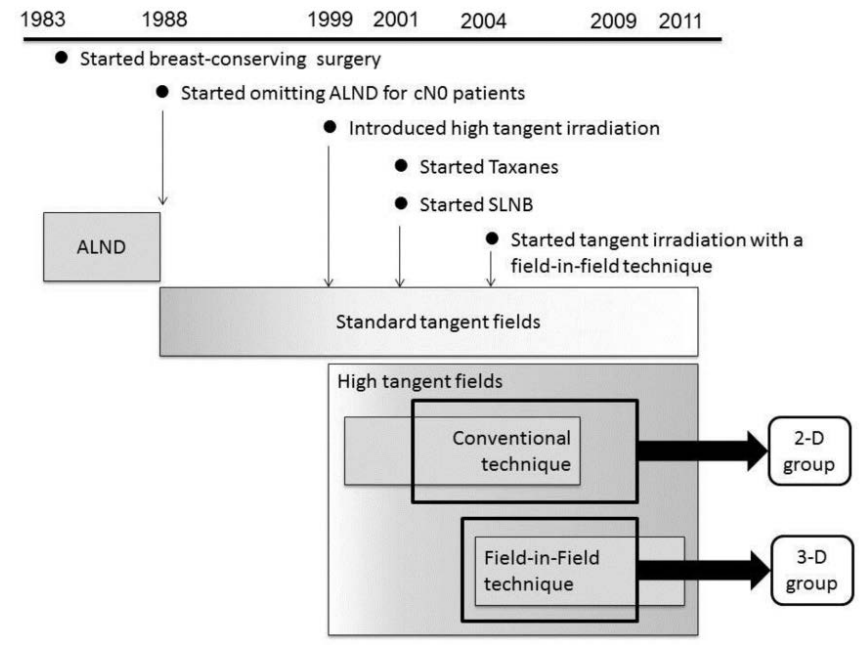

Fig. 1. Schema of the treatment history at our institute (ALND = Axillary lymph node dissection; $\mathrm{cN} 0=$ clinically negative node; $\mathrm{SLNB}=$ sentinel lymph node biopsy).

from this analysis. Patients who had received regional nodal irradiation to the supraclavicular fossa were also excluded.

\section{Details of Treatment}

Details of the breast-conserving treatment were reported previously [6]. Briefly, after surgery, patients received postoperative breast and axillary irradiation with high tangent fields to a total dose of $50 \mathrm{~Gy}$ in 25 fractions with or without boost irradiation to the tumor bed. The cranial edge of a tangent field was set to the caudal edge of the humeral head or above $[8,9]$. In earlier years, radiation treatment planning was performed primarily with 2-D treatment planning at either of the 2 other group hospitals. This group was the 2-D group.

In 2004, our institution introduced radiation therapy using CT-based treatment planning with a specific treatment system (FOCUS XiO version 4.2-3, CMS, St. Louis, MO, USA). Details of this type of treatment planning were reported previously [7]. In brief, for typical high tangent breast irradiation, the clinical target volume included the whole breast and the level I-II axillary nodal regions. After the dose distribution with the original tangential fields was calculated, the second set of fields was designed to avoid the hot region (a field-in-field technique). This group was the 3-D group.

For selected patients, adjuvant systemic therapy with chemotherapy, hormonal therapy, or both were given, with the decision based on individual risks. In earlier years, patients treated with chemotherapy received cyclophosphamide, methotrexate, and fluorouracil (CMF) or doxorubicin-based regimens. More recently, taxanes, with or without trastuzumab, have been added to doxorubicin-based chemotherapy, depending on the risk profile of the patient. Tamoxifen, with or without a luteinizing hormone-releasing hormone analogue agent, or an aromatase inhibitor was also given, as appropriate.

\section{Follow-Up}

Patients were followed up on an outpatient basis with interviews, laboratory data review, physical examination, mammography, and breast ultrasound at 3-6-month intervals during the first 2 years after the date of breast surgery, and every 6 months thereafter. Local recurrences were determined by pathological confirmation. Regional nodal failure (RNF) was diagnosed either by radiological findings or positive regional lymph node biopsy results. Lymph node recurrences in the axilla, ipsilateral infra- or supraclavicular fossa, or both were defined as RNF. Lymph node 
Table 1. Patient characteristics

\begin{tabular}{|c|c|c|c|}
\hline & 2-D planning group & 3-D planning group & $\mathrm{p}$ value \\
\hline Total number, $\mathrm{n}$ & 346 & 332 & \\
\hline Age at diagnosis, median (range) years & $52(22-80)$ & $57(22-88)$ & $<0.001$ \\
\hline Premenopausal patients, n (\%) & $168(49)$ & $112(34)$ & $<0.001$ \\
\hline Tumor stage (pathological), n (\%) & & & 0.1 \\
\hline I & $194(56)$ & $206(62)$ & \\
\hline II & 149 (43) & $121(36)$ & \\
\hline III & $3(1)$ & $5(2)$ & \\
\hline Pathological size of primary tumor, median (range), $\mathrm{cm}$ & $2.0(0.1-6)$ & $2.0(0.1-7)$ & 0.09 \\
\hline Estrogen receptor status, $\mathrm{n}(\%)$ & & & 0.71 \\
\hline Positive & $274(79)$ & $259(78)$ & \\
\hline Negative & $72(21)$ & $73(22)$ & \\
\hline Progesterone receptor, status n (\%) & & & 0.38 \\
\hline Positive & $229(66)$ & $209(63)$ & \\
\hline Negative & 117 (34) & $123(37)$ & \\
\hline HER-2 overexpression, n (\%) & & & 0.05 \\
\hline Positive & $46(13)$ & $28(9)$ & \\
\hline Negative & $300(87)$ & $303(91)$ & \\
\hline Lymphovascular invasion, $\mathrm{n}(\%)$ & & & $<0.001$ \\
\hline Present & $113(33)$ & $229(69)$ & \\
\hline Absent & $233(67)$ & $103(31)$ & \\
\hline Nuclear grade, $\mathrm{n}(\%)$ & & & 0.83 \\
\hline $1-2$ & $304(88)$ & $289(87)$ & \\
\hline$\geq 3$ & 40 (12) & 40 (13) & \\
\hline Histology, n (\%) & & & 0.5 \\
\hline Ductal & $313(91)$ & $308(93)$ & \\
\hline Lobular & $4(1)$ & $2(1)$ & \\
\hline Other & $29(8)$ & $22(7)$ & \\
\hline Lymph node metastases, $\mathrm{n}(\%)$ & & & $<0.001$ \\
\hline Unknown & $275(79)$ & 37 (11) & \\
\hline Negative by sentinel node biopsy & $71(21)$ & $295(89)$ & \\
\hline Adjuvant chemotherapy, $\mathrm{n}(\%)$ & $231(67)$ & 57 (17) & $<0.001$ \\
\hline Adjuvant hormone therapy, n (\%) & $140(40)$ & $253(76)$ & $<0.001$ \\
\hline
\end{tabular}

recurrences that occurred simultaneously with distant metastasis, inbreast recurrence, or a new contralateral breast carcinoma were scored as events. However, for the purposes of evaluating regional nodal failure in this study, any subsequent lymph node recurrences in a patient were not scored as an RNF event, because of the potential confounding effect of further dissemination or treatment. Isolated axillary failure or RNF preceding distant metastasis, with or without ipsilateral breast recurrence, was also evaluated. Toxicity was graded using version 3.0 of the National Cancer Institute Common Toxicity Criteria.

\section{Statistical Analysis}

The chi-square test, Fisher's exact test, and the Mann-Whitney U test were used to compare characteristics between groups. Cumulative lymph node recurrence rates and overall survival rates were calculated with the Kaplan-Meier method, and survival curves classified by each axillary treatment were compared with a log-rank test. Univariate and multivariate Cox regression analyses were used to determine if any clinical or treatment-related variables were predictors of axillary failure. Univariate factors with $\mathrm{p}<0.10$ were included in multivariate analysis. A p value of $<0.05$ was considered statistically significant. The statistical calculations were performed with IBM SPSS Statics 20.0 (IBM Corp., Armonk, NY, USA).

\section{Results}

In total, 678 patients were eligible, and were divided into the following 2 groups: the 2-D group $(\mathrm{n}=346)$ and the 3-D group $(\mathrm{n}=332)$. As of May 31, 2009, the median follow-up times for the 2-D and 3-D groups were 94 months (range 3-131 months) and 52 months (range 2-104 months), respectively. $12(1.7 \%)$ survivors were lost to follow-up within 12 months, and $20(2.9 \%)$ were lost between 12 months and 2 years after surgery. Patient demographics, tumor characteristics, and therapeutic regimen are shown in table 1. Compared with the 3-D group, patients in the 2-D group were statistically significantly younger and statistically significantly more were premenopausal. In contrast, the percentage of patients with tumors with lymphovascular invasion was larger in the 3-D group. Other characteristics were well balanced.

Univariate analysis revealed that 2-D planning, age, nodal status, and not using hormonal therapy were predictors for axillary failure. Multivariate analysis revealed that 2-D planning influenced axillary failure $(\mathrm{p}=0.005$; hazard ratio 9.430, 95\% confidence interval 1.195-74.391).

Overall, there were 16 regional recurrences. The median time to develop regional failure was 31 months (range 9-98 months) and 34 months $(\mathrm{n}=1)$ in the 2-D and 3-D groups, respectively. The 5-year cumulative incidence of axillary failure for the 2-D and 3-D groups, respectively, was 8 (3.1\%) and $1(0.3 \%)(\log$-rank $\mathrm{p}=0.009)$; the 5 -year cumulative incidence of RNF was $11(4.2 \%)$ and $1(0.3 \%)(p=0.001)$ (fig. 2 A, B), respectively. The 5-year cumulative incidence of ipsilateral breast failure in the 2-D and 3-D groups, respectively, was $7(2.5 \%)$ and $1(0.3 \%)(p=0.048)$, and that of 


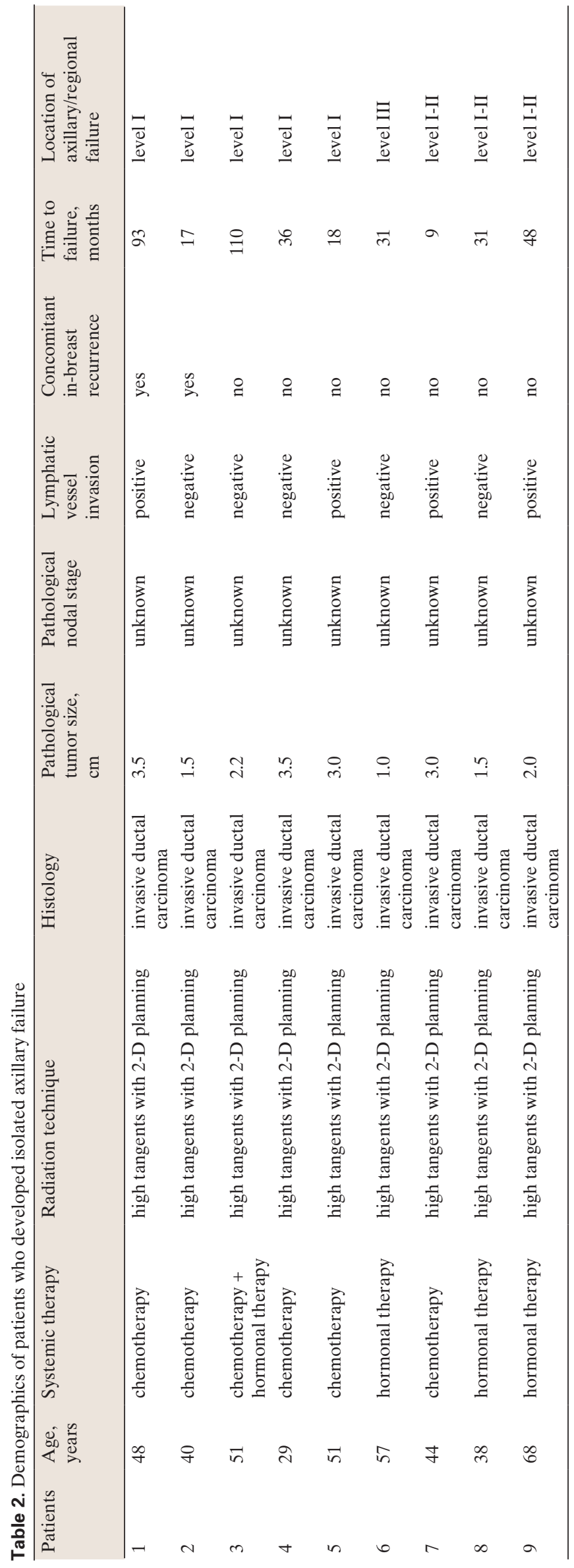

distant metastasis $16(7.1 \%)$ and $4(1.2 \%)(\mathrm{p}=0.005)$. The respective 5-year cancer-specific and overall survival rates were 98.1 and $99.0 \%(\mathrm{p}=0.32)$ and 97.4 and $98.4 \%(\mathrm{p}=0.4)$ (fig. 2 C).

Symptomatic radiation pneumonitis not necessitating oxygen therapy developed in $5 / 3(1.4 / 0.9 \%)$ patients in the $2-\mathrm{D}$ and 3-D group, respectively. No patient had persistent pulmonary symptoms. $2 / 0(0.6 / 0 \%)$ patients developed mild arm edema (grade 1). Mild shoulder constriction due to SLNB was observed in 1 patient in the 2-D group. No brachial plexopathy was observed in all patients.

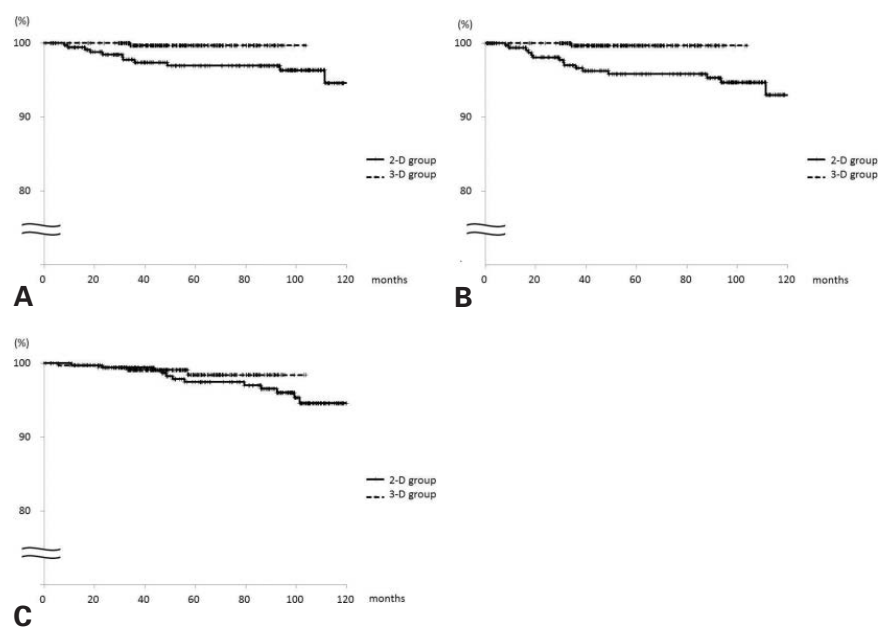

Fig. 2. A Axillary and $\mathbf{B}$ regional nodal control, and $\mathbf{C}$ overall survival according to radiation treatment planning (solid line: 2-D group; dashed line: 3-D group).
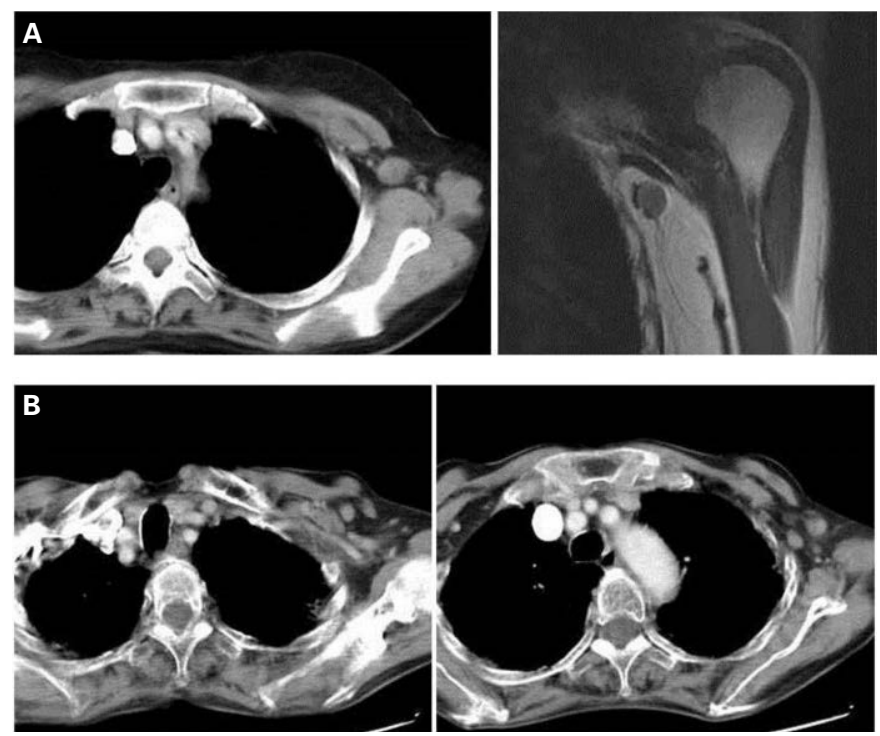

Fig. 3. A Computed tomography (CT) scan and magnetic resonance imaging of a 51-year-old patient who had isolated axillary recurrence 18 months after surgery. The lymph node with recurrence was located in the level I axilla. B CT scan of a 68-year-old patient who had multiple enlarged nodes in both the level I and II regions 48 months after surgery. 
Table 2 shows the demographics of 9 patients who developed isolated axillary failure with or without local or supra-/ infraclavicular failure, which could still be treated with local salvage therapy. All were in the 2-D group. 5 recurred within the level I axilla, but 2 had concomitant in-breast recurrence, suggesting that they were radioresistant. Figure 3 A shows a 51-year-old patient (Patient 5) with isolated nodal recurrence in the level I axilla 18 months after surgery. There were 4 other patients who developed axillary recurrence beyond level I. Among them was a 68-year-old patient (Patient 9) who had multiple enlarged nodes in both the level I and II regions 48 months after surgery (fig. $3 \mathrm{~B}$ ).

\section{Discussion}

In the current study, the 2-D planning group had younger patients. This may be relevant to more ipsilateral breast recurrences and distant failures in the 2-D group. In contrast, the patients in the 3-D group had more lymphovascular invasion. Nevertheless, multivariate analysis revealed that 2-D planning was the only risk factor for axillary failure. In fact, the log-rank test showed that 3-D planning yielded better axillary and regional control, suggesting that better dose istribution by 3-D-treatment planning could better control the axilla. Of the 9 patients who developed isolated axillary failure (table 2), 3 patients had recurrence from level I axilla without in-breast recurrence. These patients (e.g., fig. 3 A) may have been successfully treated by high tangents with a field-in-field technique. On the other hand, other patients (e.g., fig. 3 B) could have possibly been a candidate for a separate third field to the supraclavicular fossa. However, no possible risk factors for optimal treatment field were observed in those 9 patients.

The optimal design of radiation fields for patients with positive SLNs, who do not undergo ALND, is uncertain. The results of the American College of Surgeons Oncology Group (ACOSOG) trial Z0011 demonstrated equivalent survival in patients with breast cancer and positive SLNs, who were randomly assigned to SLNB alone or SLNB followed by ALND [3]. Regional recurrence with SLNB alone was less than $1 \%$, in spite of an estimated $27 \%$ of additional non-SLN involvement. As one of the reasons for the equivalent regional control, tangential field radiation may have coincidently delivered radiation treatment to the lower axilla and eradicated the disease.

Before the diffusion of CT-based radiotherapy planning, many clinicians believed that the lower axillary nodes were usually included in the tangential fields [10]. However, dosedistribution analysis indicated that the entire volume of the axilla is not irradiated with the entire prescribed dose. It is now estimated that, using standard tangential fields, more than $50 \%$ of level I and $20-30 \%$ of level II nodes receive $95 \%$ of the prescribed radiation dose $[8,9,11,12]$. The advantage of the field-in-field plan over the conventional wedge-inserted plan was also demonstrated in other reports $[7,13]$. Although the Z0011 protocol did not allow regional nodal irradiation, it is said that ACOSOG is currently working to extract the data on whether the radiation oncologist used high tangents to treat more of the level I and II nodes. This study will add more information on optimal field design for $\mathrm{cN} 0$ patients.

Haffty et al. [14] suggested an approach to assess the risk of microscopic involvement and select optimal radiation for radiation field design. However, the risk may vary by institution, and a careful application of the risk-adapted approach is needed. In fact, although standard practice is to use Tc $(99 \mathrm{~m})$ sulfur colloid to identify SLNs, we used blue dye, a practice that may lead to false-negative SLNB in some cases. While there are many findings to suggest the value of full nodal irradiation, particularly for patients with $1-3$ positive nodes $[15,16]$, it is very difficult to draw clear lines for standard tangents, high tangents, or regional nodal irradiation with a separate third field. For all of these reasons, high tangents are now routinely used for SLN-negative patients, and full nodal irradiation is principally applied for SLN-positive patients in our institution. Our long experience of treating $\mathrm{cN} 0$ patients without ALND before the SLNB era lead to the liberal use of regional nodal irradiation by either high tangents or regional nodal irradiation.

Limitations of this study include the between-group variations in follow-up times and the differences in the use of chemotherapy and hormonal therapy, all of which are associated with the retrospective nature of this study. In contrast, the strength of this study is that it shows the clinical use of 3-D treatment planning to irradiate intentionally the large volume of level I and II nodes. While retrospective dosimetric studies have suggested the technical use of high tangent fields [7, 1113], this is the first study to demonstrate the impact of improved dose distribution on regional control in breast cancer management.

In conclusion, high tangent irradiation with 3-D treatment planning with a field-in-field technique improved regional control compared to high tangent fields with 2-D treatment planning in patients with $\mathrm{cN} 0$ breast cancer. The results suggest that optimizing axillary dose distribution may impact outcomes.

\section{Disclosure Statement}

The authors declare no conflicts of interests. 


\section{References}

1 Gentilini O, Botteri E, Rotmensz N, Da Lima L, Caliskan M, Garcia-Etienne CA, Sosnovskikh I, Intra M, Mazzarol G, Musmeci S, Veronesi P, Galimberti V, Luini A, Viale G, Goldhirsch A, Veronesi U: Conservative surgery in patients with multifocal/multicentric breast cancer. Breast Cancer Res Treat 2009;113:577-583.

$\checkmark 2$ Intra M, Rotmensz N, Mattar D, Gentilini OD, Vento A, Veronesi P, Colleoni M, De Cicco C, Cassano E, Luini A, Veronesi U: Unnecessary axillary node dissections in the sentinel lymph node era. Eur J Cancer 2007;43:2664-2668.

3 Giuliano AE, Hunt KK, Ballman KV, Beitsch PD, Whitworth PW, Blumencranz PW, Leitch AM, Saha S, McCall LM, Morrow M: Axillary dissection vs. no axillary dissection in women with invasive breast cancer and sentinel node metastasis: a randomized clinical trial. JAMA 2011;305:569-575.

4 National Comprehensive Cancer Network: NCCN Clinical Practice Guidelines in Oncology: Breast Cancer. www.nccnorg/professionals/physician_gls/ pdf/breastpdf, updated March 11, 2013.

$\checkmark 5$ Fujimoto N, Amemiya A, Kondo M, Takeda A, Shigematsu N: Treatment of breast carcinoma in patients with clinically negative axillary lymph nodes using radiotherapy versus axillary dissection. Cancer 2004;101:2155-2163.

-6 Sanuki N, Takeda A, Amemiya A, Ofuchi T, Ono M, Ogata H, Yamagami R, Hatayama J,
Eriguchi T, Kunieda E: Outcomes of clinically node-negative breast cancer without axillary dissection: can preserved axilla be safely treated with radiation after a positive sentinel node biopsy? Clin Breast Cancer 2013;13:69-76.

$>7$ Ohashi T, Takeda A, Shigematsu N, Fukada J, Sanuki N, Amemiya A, Kubo A: Dose distribution analysis of axillary lymph nodes for three-dimensional conformal radiotherapy with a field-in-field technique for breast cancer. Int J Radiat Oncol Biol Phys 2009;73:80-87.

8 Takeda A, Shigematsu N, Ikeda T, Kawaguchi O, Kutsuki S, Ishibashi R, Kunieda E, Takeda T, Takemasa K, Ito H, Uno $\mathrm{T}$, Jinno $\mathrm{H}$, Kubo A: Evaluation of novel modified tangential irradiation technique for breast cancer patients using dosevolume histograms. Int J Radiat Oncol Biol Phys 2004;58:1280-1288.

$\checkmark$ Takeda A, Shigematsu N, Kondo M, Amemiya A, Kawaguchi O, Sato M, Kutsuki S, Toya K, Ishibashi R, Kawase T, Tsukamoto N, Kubo A: The modified tangential irradiation technique for breast cancer: how to cover the entire axillary region. Int J Radiat Oncol Biol Phys 2000;46:815822.

10 Recht A, Houlihan MJ: Axillary lymph nodes and breast cancer: a review. Cancer 1995;76:1491-1512.

11 Alco G, Igdem SI, Ercan T, Dincer M, Senturk R, Atilla S, Oral Zengin F, Okkan S: Coverage of axil- lary lymph nodes with high tangential fields in breast radiotherapy. Br J Radiol 2010;83:10721076.

12 Reznik J, Cicchetti MG, Degaspe B, Fitzgerald TJ: Analysis of axillary coverage during tangential radiation therapy to the breast. Int J Radiat Oncol Biol Phys 2005;61:163-168.

13 Onal C, Sonmez A, Arslan G, Oymak E, Kotek A, Efe E, Sonmez S, Dolek Y: Dosimetric comparison of the field-in-field technique and tangential wedged beams for breast irradiation. Jpn J Radiol 2012;30:218-226.

14 Haffty BG, Hunt KK, Harris JR, Buchholz TA: Positive sentinel nodes without axillary dissection: implications for the radiation oncologist. J Clin Oncol 2011;29:4479-4481.

15 Whelan T, Olivotto I, Ackerman I: NCIC-CTG MA20: an intergroup trial of regional nodal irradiation in early breast cancer. J Clin Oncol 2011; 29:80s(abstr LBA1003).

16 Overgaard M, Nielsen HM, Overgaard J: Is the benefit of postmastectomy irradiation limited to patients with four or more positive nodes, as recommended in international consensus reports? A subgroup analysis of the DBCG 82 b\&amp;c randomized trials. Radiother Oncol 2007;82:247253. 